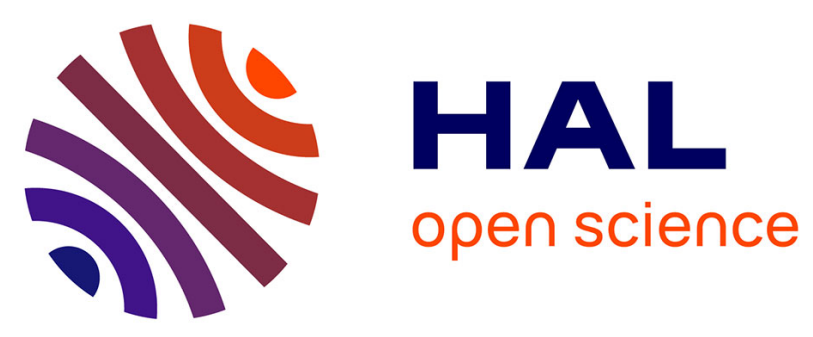

\title{
Voltammetric determination of ascorbic acid with zinc oxide modified glassy carbon electrode
}

Nadia Ait Ahmed, Hammache Houa, Marielle Eyraud, Carine Chassigneux, Florence Vacandio, Philippe Knauth, Laid Makhloufi, Nour-Eddine Gabouze

\section{- To cite this version:}

Nadia Ait Ahmed, Hammache Houa, Marielle Eyraud, Carine Chassigneux, Florence Vacandio, et al.. Voltammetric determination of ascorbic acid with zinc oxide modified glassy carbon electrode. Journal of the Iranian Chemical Society, 2019, 16 (9), pp.1957-1963. 10.1007/s13738-019-01668-5 . hal-02470781

\section{HAL Id: hal-02470781 \\ https: / hal-amu.archives-ouvertes.fr/hal-02470781}

Submitted on 7 Feb 2020

HAL is a multi-disciplinary open access archive for the deposit and dissemination of scientific research documents, whether they are published or not. The documents may come from teaching and research institutions in France or abroad, or from public or private research centers.
L'archive ouverte pluridisciplinaire HAL, est destinée au dépôt et à la diffusion de documents scientifiques de niveau recherche, publiés ou non, émanant des établissements d'enseignement et de recherche français ou étrangers, des laboratoires publics ou privés. 


\title{
Voltammetric determination of ascorbic acid with zinc oxide modified glassy carbon electrode
}

Nadia Ait Ahmed ${ }^{1, *} \cdot$ Houa Hammache ${ }^{1} \cdot$ Marielle Eyraud $^{2} \cdot$ Carine Chassigneux $^{2} \cdot$ Florence Vacandio $^{2}$ $\cdot$ Philippe Knauth $^{2} \cdot$ Laid Makhloufi $^{1}{ }^{\circ}$ Nour-eddine Gabouze ${ }^{3}$

${ }^{1}$ Laboratoire d'Electrochimie, de Corrosion et de Valorisation Energétique(LECVE), Université de Bejaia, 06000 Bejaia, Algérie.

${ }^{2}$ Aix-Marseille Univ, CNRS, MADIREL UMR 7246, équipe Electrochimie des Matériaux, 13013 Marseille, France.

3 Centre de Recherche en Technologie des Semiconducteurs pour l'Energétique (CRTSE), 2bvd. Frantz

Fanon, B.P. 140 Alger 7 Merveilles, Alger, Algérie.

Corresponding author: naitahmed213@gmail.com

\begin{abstract}
Zinc oxide $(\mathrm{ZnO})$ nanostructures electrodeposited from aqueous zinc nitrate solution at $70{ }^{\circ} \mathrm{C}$ onto glassy carbon electrode (GCE) were used as electrochemical detectors. The morphology, structure, chemical composition and conductivity of the as-deposited layers were determined using Scanning Electron Microscopy, X-Ray Diffraction, Energy Dispersive X-ray analysis and UV-vis spectroscopy. A highly oriented crystalline $\mathrm{ZnO}$ deposit made of a dense array of randomly oriented hexagonal nanorods was obtained without any additives in solution. The electrocatalytic oxidation of Ascorbic Acid (AA) was studied using cyclic voltammetry in $0.1 \mathrm{M}$ phosphate buffer solution at $\mathrm{pH}$ 6.8. Comparing the response for AA oxidation on the bare and modified electrodes, the peak potential was shifted to $-0,45 \mathrm{~V}$ on $\mathrm{ZnO} / \mathrm{GCE}$ with higher current densities and transfer coefficient, due to a simultaneous increase of oxidation rate and surface area. A linear relationship was determined between the anodic peak current and the AA concentration in the range of 0.1 to $5 \mathrm{mM}$.
\end{abstract}

Keywords: $\mathrm{ZnO}$ electrodeposition • Electrocatalysis • Eectrochemical sensor ${ }^{`}$ Ascorbic acid oxidation $\cdot$ Thin films.

\section{Introduction}

Ascorbic Acid (AA) is a soluble vitamin present in many biological systems and in multivitamin preparations, which are commonly used extensively as an antioxidant in food, animal feed beverage, pharmaceutical formulations, and cosmetic application [1]. AA plays also an important role in collagen production, a protein needed for the development and 
maintenance of bones, cartilage, joint linings, skin, teeth, gums and blood vessels. Besides, AA takes part in the human metabolism, including amino acid digestion, synthesis of adrenalin, anti-inflammatory steroids and certain hormones and neurotransmitters [2]. In view of these functionalities, inexpensive, rapid and reliable method to determine the AA concentration attracts great attention in biomedical engineering, food and pharmaceutical industries. The generally employed analytical methods are fluorimetry, chromatography, iodometric titration, enzymatic methods, spectroscopy and electrochemistry [3-5]. Potentiometric and amperometric methods are based on the electrochemical behavior of AA [6] that can be either in oxidized form (L-dehydroascorbic acid) or in reduced state (Lascorbic acid) according to the following equilibrium (1) [7]:

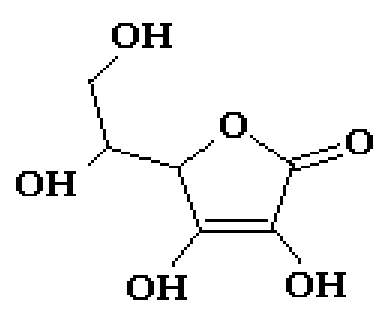

L-ascorbic acid

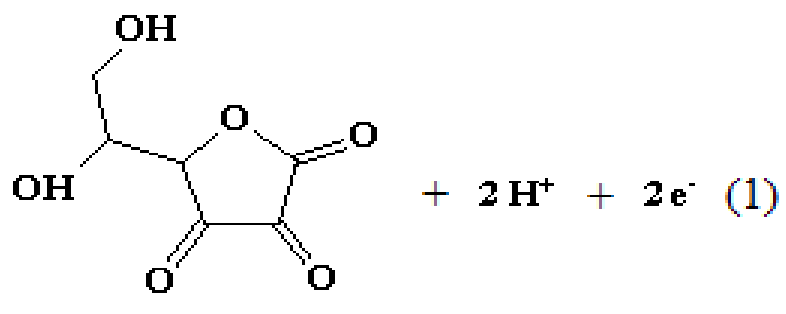

L-dehydroascorbic acid

Voltammetric techniques are considered important, because they allow the determination of trace concentrations of many biological elements. However, the direct electrochemical oxidation of $\mathrm{AA}$ at bare electrodes, including carbon, $\mathrm{Hg}, \mathrm{Au}$ or $\mathrm{Pt}$, requires a high overpotential and showed poor sensitivity, low selectivity and poor reproducibility. Because of the high electrochemically active area as well as excellent electronic transfer capability, many scholars have adopted these structures as sensing materials to modify electrode surfaces while developing AA sensors of high sensitivity and good selectivity. Thus, numerous attempts were made to enhance the electrode kinetics using various chemically modified electrodes $[\mathbf{8}, \mathbf{9}]$ by adding several metallic and non-metallic nanomaterials to the carrier substrate [10-12]. Among them, zinc oxide is one of the most promising materials for nanotechnology due to its broad area of applications, such as sensors, solar energy, light emission, photo-catalysis and nano-generators [13]. Furthermore, $\mathrm{ZnO}$ has been used extensively in the field of electrochemical sensing due to its properties such as high conductivity, low cost, high chemical stability, ease of synthesis and electrocatalytic activity, 
especially for the detection of traces of biomolecules, such as AA [14-17]. A recent work has shown that the existence of $\mathrm{ZnO}$ in $\mathrm{RGO}-\mathrm{ZnO} / \mathrm{GCE}$ largely enhanced the electroactive surface area and therefore the sensitivity for electrochemical sensing [18]. S. Ashok Kumar [19] designed an electrochemical ascorbic acid sensor with excellent performance based on $\mathrm{ZnO}$ /poly-luminol hybrid films.

Glassy carbon was widely used as modifiable electrode material for the design of electrochemical sensors, due to its high electrical conductivity, its good resistance to chemical attack and its suitability in a large potential range. Many studies were already reported on the electrocatalytic activity of glassy carbon electrodes (GCE) modified by nanoparticles and /or polymer films [20-24]. Hybrid materials such as carbon fibers covered by $\mathrm{ZnO}$ [25, 26] or $\mathrm{ZnO} /$ carbon nanotube nanocomposites [27] were used for the detection of biomolecules, such as AA, dopamine, uric acid or adrenaline. Zhang and coworkers [15] revealed that the presence of $\mathrm{ZnO}$ in reduced graphene oxide- $\mathrm{ZnO} / \mathrm{GCE}$ largely enhanced the electroactive surface area and therefore the sensitivity for simultaneous electrochemical detection of AA and contaminants, including dopamine and uric acid. In a recent paper [28], it was shown that $\mathrm{ZnO}$ nanorods prepared by a hydrothermal method could be desiccated to prepare $\mathrm{ZnO} / \mathrm{GCE}$. This modified electrode allowed AA detection with a rapid response and a low detection limit $(0,27 \mu \mathrm{M})$. However, the preparation of this kind of electrode required two steps ( $\mathrm{ZnO}$ preparation and integration on GCE), which is less convenient than a one step preparation by electrodeposition. To our knowledge, there exists no work where $\mathrm{ZnO}$ modified GCE for AA detection were fabricated in one-step by electrodeposition.

In this study, we explore the feasibility of the electrochemical synthesis of $\mathrm{ZnO}$ nanorod arrays on GCE for the fabrication of a rapid, reliable and nanosized detector of AA oxidation.

\section{Experimental}

All chemicals were of analytical grade and the aqueous solutions were prepared with milli-Q water (18.2 M $\Omega$, Milli-Q, Millipore system). Zinc nitrate $\left(\mathrm{Zn}\left(\mathrm{NO}_{3}\right)_{2}\right)$, L-ascorbic acid (AA) and potassium nitrate $\left(\mathrm{KNO}_{3}\right)$ were purchased from Sigma-Aldrich and Fluka (98\%) respectively. Phosphate buffer solutions were prepared from potassium dihydrogenophosphate $\left(\mathrm{KH}_{2} \mathrm{PO}_{4}\right)(99 \%)$ and dipotassium hydrogenophosphate $\left(\mathrm{K}_{2} \mathrm{HPO}_{4}\right)(97 \%)$ purchased from Prolabo.

Before the electrochemical measurements, GCE were mechanically polished using 1000 and 2400 silicon carbide papers, followed by $6-\mu \mathrm{m}$ diamond paste on an appropriate cloth. Finally, the surface was cleaned during $5 \mathrm{~min}$ in milli-Q water in an ultrasonic bath. 
Electrochemical measurements were performed using a potentiostat/galvanostat (Autolab PGSTAT30). The electrodeposition was carried out in a classical three-electrode system. A bare GCE of $1.8 \mathrm{~cm}^{2}$ or $\mathrm{ZnO}$ electrodeposited on glassy carbon ( $\left.\mathrm{ZnO} / \mathrm{GCE}\right)$ were employed as working electrodes. A large platinum foil was the counter electrode and a saturated calomel electrode (SCE) served as reference. All potentials were recorded with respect to this reference electrode.

$\mathrm{ZnO}$ nanostructures were synthesized from $0.1 \mathrm{M} \mathrm{KNO}_{3}$ solution containing $5 \mathrm{mM} \mathrm{Zn}\left(\mathrm{NO}_{3}\right)_{2}$ with an initial $\mathrm{pH}$ value of 6.5 at $70{ }^{\circ} \mathrm{C}$, using a deposition potential of $-1.1 \mathrm{~V}$. The deposition duration varied between 5 and $20 \mathrm{~min}$. The solution was carefully de-aerated under argon flow 20 min before and during the experiment.

The surface morphology and composition of $\mathrm{ZnO} / \mathrm{CGE}$ were investigated by Scanning Electron Microscopy (SEM) (Hitachi, S-570) equipped with Energy Dispersive X-ray Spectroscopy (EDX). X-ray Diffraction (XRD) was performed on a Siemens D5000 diffractometer using filtered $C u K \alpha(\lambda=0.15406 \mathrm{~nm})$. The diffractometer was operated at 40 $\mathrm{kV}$ and $40 \mathrm{~mA}$, room temperature, with a scanning rate of $1.2^{\circ} \mathrm{min}^{-1}$ and for scattering angles $2 \theta$ ranging from $30^{\circ}$ to $50^{\circ}$. UV visible diffuse absorption spectra of the samples were recorded at room temperature in the range of $300-800 \mathrm{~nm}$ using a Varian 300 spectrophotometer equipped with an integrating sphere DRA-CA-30I on a Hitachi U-3310.

\section{Results and discussion}

\section{Chronoamperometry}

Figure 1 displays the current transient recorded for an applied potential of $-1.1 \mathrm{~V}$ on a glassy carbon substrate. The current density during the process is quite high (about $-1.7 \mathrm{~mA} / \mathrm{cm}^{2}$ after $17 \mathrm{~s}$ of growth), which confirms that the deposit is a good electronic conductor. An important feature of the curve is the presence of a cathodic wave at low deposition time (see inset part in the figure), which is assigned to the nucleation-growth process of $\mathrm{ZnO}$ on the glassy carbon substrate [29].

\section{Characterization of $\mathrm{ZnO}$ thin film}

The X-ray diffraction pattern of a $\mathrm{ZnO}$ coating deposited during 5 min on GCE is presented in Fig. 2. There is only one intense diffraction peak at $34.5^{\circ}$, and three tiny peaks at $31.9^{\circ}, 36.5^{\circ}$ and $47.6^{\circ}$. They all correspond to the hexagonal Wurtzite structure of $\mathrm{ZnO}$ (JCPDS no. 36- 
1451) with a strong preferential orientation along the c-axis. No other diffraction peaks from impurities were detected.

Figure 3 shows SEM images of the $\mathrm{ZnO}$ deposit. Uniformly shaped and oriented nanorods emerge with a partial coverage of the substrate. They form flower-like structures; each nanorod corresponds to a petal, some of them attached to the others in the heart of the crystalline flower. At higher magnification (Fig. 3b), the nanorods present faceted hexagonal structures in good agreement with XRD results. Their dimensions are quite homogeneous with around 200 to $300 \mathrm{~nm}$ width in the widest part of the rods and a length between 1 and 1.5 $\mu \mathrm{m}$.

The chemical composition investigated by EDX (Fig. 3c) indicates only peaks coming from $\mathrm{Zn}$ and $\mathrm{O}$ without impurity elements. To quantify the ratio between the elements, the analysis was repeated 5 times with the same magnification at different places. The integration of the peak area using ZAF correction software, removing the background and using deconvolution models, gives $51 \pm 4$ at $\% \mathrm{Zn}$ and $49 \pm 2$ at $\% \mathrm{O}$, in good accordance with the $\mathrm{ZnO}$ stoichiometry.

Figure 4 shows the optical absorption spectra of the same sample. According to Tauc, the dependence of the absorption coefficient $\alpha$ on the photon energy $h v$ for near-edge optical absorption in semiconductors takes the form (2):

$$
(\alpha h v)^{1 / m}=k(h v-E g)
$$

Where $E g$ is the optical band gap, $k$ is a constant and $m$ can take the values of $1 / 2$ in the case of an allowed direct energy gap transition and $3 / 2$ for a forbidden direct energy gap transition $[30,31]$. In order to determine the optical band gap of $\mathrm{ZnO}$ nanorods taking $m=1 / 2,(\alpha h v)^{2}$ was plotted versus $h v$ using the data obtained from the optical absorption spectra (Fig. 4). The direct band gap of $\mathrm{ZnO}$ nanorods was determined by extrapolating the linear part of the curve to the ordinate axis: $\sim 3.37 \pm 0.02 \mathrm{eV}$. This value agrees well with those reported for electrodeposited $\mathrm{ZnO}$ films (3.28-3.42 eV [32]).

\section{Electrocatalytic oxidation of ascorbic acid}

Figure 5 shows cyclic voltammograms (CV) obtained in $0.1 \mathrm{M}$ phosphate buffer solution (PBS) (pH 6.8) with or without $5 \mathrm{mM} \mathrm{AA}$ at a scan rate of $8 \mathrm{mV} \mathrm{s}^{-1}$. In curve 5 a, obtained on bare GCE without AA, the oxidation current is nearly zero. When AA was added to PBS, an oxidation peak appeared (curve $5 \mathrm{~b}$ ) at $0.2 \mathrm{~V}$, with a maximum current density $i_{p}=0.49$ $\mathrm{mA} \cdot \mathrm{cm}^{-2}$ at a potential $E_{p}$ of $0.55 \mathrm{~V}$. This peak corresponds to the oxidation of AA to dehydroascorbic acid according to reaction (1) [7]. No signal was observed on the reverse 
scan, even if the potential was decreased down to $-0.5 \mathrm{~V}$, indicating an irreversible electrochemical reaction.

On $\mathrm{ZnO}$ modified GCE (curve 5c), the anodic wave of AA was observed from $-0.1 \mathrm{~V}$ with a displacement of $0.3 \mathrm{~V}$ to less anodic potentials relative to bare GCE. The peak current density is nearly double $\left(0.91 \mathrm{~mA} . \mathrm{cm}^{-2}\right)$, as well as the slope to reach this current maximum. This increase in AA oxidation rate can be attributed to a larger effective electroactive surface area (shown in SEM observations) or to an electrocatalytic effect.

In the case of an irreversible system, the values of $\alpha n$ (where $n$ is the total number of electrons involved in the process and $\alpha$ the transfer coefficient) can be calculated at both modified and unmodified carbon electrodes, according to equation (3) [33]:

$$
\alpha n=0.048 /\left(E_{p}-E_{p / 2}\right)=0.048 / \Delta E
$$

Where $E_{p}$ is the peak potential and $E_{p / 2}$ is the potential corresponding to $i_{p / 2}$ (half of the maximum in current). The $\Delta E$ values were found to be $0.08 \mathrm{~V}$ and $0.19 \mathrm{~V}$ on $\mathrm{ZnO} / \mathrm{CGE}$ and CGE respectively. Assuming $n=2$ [34], the $\alpha$ value calculated on the modified electrode was 0.29 , against 0.13 on the bare electrode. These values clearly show that the rate of the electron transfer process is greatly enhanced at the surface of $\mathrm{ZnO} / \mathrm{GCE}$. These two observations indicate an electrocatalytic effect on the modified electrode.

\section{Effect of the deposition time on the electrocatalytic oxidation of AA}

In order to increase the sensitivity of the electrochemical detection at $\mathrm{ZnO} / \mathrm{GCE}$, the experimental conditions have to be optimized. First, $\mathrm{ZnO}$ electrodeposits were obtained using the previous conditions, but for various times between 5 and 20 min. Cyclic voltamogramms (Fig. 6) show that the deposition time has a crucial effect on the electrocatalytic response: the intensity of the AA oxidation peak decreases and the potential moves towards more positive values when the deposition time increases.

This behavior can be related to changes of the morphology of $\mathrm{ZnO}$ deposits, as already mentioned in previous papers $[35,36]$. Further experiments were then made on the optimized $\mathrm{ZnO}$ electrode obtained at $-1.1 \mathrm{~V}$ during $5 \mathrm{~min}$.

\section{Influence of the scan rate}

Figure 7 shows the scan rate dependence of cyclic voltammograms. An enhancement of the scan rate from 8 to $300 \mathrm{mV} . \mathrm{s}^{-1}$ induces slight anodic shifts of the peak potential. Similar 
results were observed by Raoof et al. for AA oxidation on a modified carbon paste electrode $[37,38]$. This behavior confirms the kinetic limitation of the electrochemical reaction. As shown in Fig. 7 b, the peak current varies linearly with the square root of the scan rate, which indicates that the electrocatalytic process is controlled by AA diffusion to the electrode surface [39].

\section{Effect of AA concentration}

The CV responses for different concentrations of AA $(0.1-5 \mathrm{mM})$ are presented in Fig. 8 a. The oxidation current increased with increasing AA concentration.

Figure $8 \mathrm{~b}$ shows the calibration plots (peak current vs. AA concentration): the current increases linearly in the range of $0.1-5 \mathrm{mM}$ following an equation: $i_{p}=0.1830 C_{A A}+0.0024$. The sensitivity of detection is high: the slope $\left(0.18 \mathrm{~mA} \cdot \mathrm{cm}^{-2} \cdot \mathrm{mM}^{-1}\right)$ is in the same order of magnitude as that found by Zhang et al [15] on reduced graphene oxide/ZnO deposited on $\operatorname{GCE}\left(0.17 \mathrm{~mA} \cdot \mathrm{cm}^{-2} \cdot \mathrm{mM}^{-1}\right)$

Moreover, our $\mathrm{ZnO} / \mathrm{CGE}$ presents a good stability towards AA oxidation, because all experiments on Figures 7 and 8 were obtained on the same $\mathrm{ZnO}$ electrode. Nevertheless, further experiments concerning the lifetime of the electrode and the presence of potentially interfering species, such as glucose, uric acid and hydrogen peroxide are in progress.

\section{Conclusion}

In conclusion, electrochemical deposition is a rapid and convenient method to obtain in onestep Glassy Carbon Electrodes (GCE) modified with $\mathrm{ZnO}$ nanorods. The morphology, composition, structure and conductivity of the $\mathrm{ZnO}$ films were determined. The as-deposited electrodes were investigated as electrocatalytic material for ascorbic acid oxidation. Compared to bare GCE, $\mathrm{ZnO} / \mathrm{GCE}$ displays higher activity towards the oxidation of ascorbic acid (AA) with a significantly lower overpotential and higher current densities and transfer coefficients. These good results can be attributed to a simultaneous increase of the electroactive surface area and the electron transfer rate. The electrocatalytic oxidation currents of AA depend linearly on the AA concentration.

\section{References}

1. H. Liu, W. Na, Z. Liu, X. Chen, X. Su, Biosens. Bioelectron. 92, (2017) 229-233

2. R. N. Castro, L.C. Azeredo, M.A.A. Azeredo, C.S.T. de Sampaio, J. Liquid. Chromato \& Related 
Techno. 24, 1015 (2001)

3. H. Bagheri, N. Pajooheshpour, B. Jamali, S. Amidi, A. Hajian, H. Khoshsafar, Microchem. J. 131, 120 (2017)

4. A. Solhjoo \& H. Khajehsharifi, Current. Anal. Chem. 12, 580 (2016)

5. A. Parsa, M. Tajik, Polish. J. Chem. Techno. 19, 125(2017)

6. R. E. Sabzi, M. H. Pournaghi-Azar, Anal. Sci. 6, 689 (2005)

7. M. A. Kamyabi, Z. Asgari, H. Hosseini Monfared, A. Morsali, J. Electroanal. Chem. 632, 170 (2009)

8. Kh. Ghanbari, A. Hajian, J. Electroanal. Chem. 801, 466 (2017)

9. L. Jothi, S. Neogi, S. k. Jaganathan, G. Nageswaran, Biosens. Bioelectron. 105, 236 (2018)

10. L. J. D. Costa, E.C. Pereira, a review, Trens. Anal. Chem. 76, 15 (2016)

11. H. R. Zare, F. J. Dehaghani, Z. Shekari, A. Benvidi, App. Surf. Sci. 375, 169 (2016)

12. B. Dinesh, R. Saraswathi, A. S. Kumar, Electrochim. Acta. 233, 92 (2017)

13. Y. Wang, J.Yang, H. Jia, M. Yu, H. Jin, J. Alloy. Compd. 665, 62 (2016)

14. H. Liu, Ch. Gu, Ch. Hou, Zh.Yin, K. Fan, M. Zhang, Sens. Actuat. B. 224, 857(2016)

15. X. Zhang, Y-Ch. Zhang, Li-Xi. Ma, Sens. Actuat. B. 227, 488 (2016)

16. H. Zhu and G. Xu, Int. J. Electrochem. Soc. 12, 3873 (2017)

17. C. Hou, H. Liu, D. Zhang, C. Yang, M. Zhang, J. Alloy. Compd, 2016, 666, 178.

18. X. Zhang, Yi.Ch. Zhang, Li. X. Ma, Sens. Actuat. B : Chem. 227, (2016) 488-496

19. S. Ashok Kumar, H-W. Cheng, S-M. Chen, React \& Funct. Polym. 69, 364 (2009)

20. L. Zhang, J. Feng, K. C. Chou, L. Su, X. Hou, J. Electroanal. Chem. 803, 11 (2017)

21. R. Zhang, S. Liu, L. Wang, G. Yang, Measurement. 46, 1089 (2013)

22. J. P. Bartolome, A. Fragoso, Inorg. Chim. Acta. 468, 223 (2017)

23. R. Ojani, J - B. Raoof, A. A. Maleki, S. Safshekan, Chin. J. Cataly. 35, 423 (2014)

24. M. Sajid, M. K. Nazal, M. Mansha, A. Alsharaa, S. M. S. Jillani, C. Basheer, A review, Trens. Anal. Chem. 76, 15 (2016)

25. L. Zhihua, Z. Xucheng, W. Kun, Z. Xiaobo, S. Jiyong, H. Xiaowei, M. Holmes, Innov. Food. Sci \& Emerg. Techno. 31, 196 (2015)

26. H. Liu, C. Gu, C. Hou, Z. Yin, K. Fan, M. Zhang, Sens .Actuat. B: Chem. 224, 857 (2016)

27. A. Pahlavan, V. K. Gupta, A. L. Sanati, F. Karimi, M. Yoosefian, M. Ghadami, Electrochim. Acta. 123, 456 (2014)

28. H. Zhu, G. Xu, Int. J. Electrochem. Sci., 12, 3878 (2017)

29. S. Fletcher, C.S. Halliday, D. Gates, M. Wetcott, T. Lwin, G. Nelson, J. Electroanal. Chem. Inter. Electrochem. 159, 267 (1983)

30. T. P. Gujar, V. R. Shinde, J.-W. Park, H. K. Lee, K.-D. Jung, O.-S. Joo, J. Electrochem. Soc. 156, E8 (2009) 
31. MC. Baykul, N. Orhan, Thin. Solid. Film. 518, 1925 (2010)

32. A. C. Aragones, A. Palacios-Padros, F. Caballero-Briones, F. Sanz, Electrochim. Acta. 109, 117 (2013)

33. E. S. Takeuchi, R. W. Murray, J. Electroanal. Chem. and Inter. Electrochem. 189, 49 (1985)

34. A. Pisoschi, A. Pop, A. Serban, C. Fafaneata, Electrochim. Acta. 121, 443 (2014)

35. N. Ait Ahmed, G. Fortas, H. Hammache, S. Sam, A. Keffous, A. Manseri, L. Guerbous, N. Gabouze, App. Surf. Sci. 256, 7442 (2010).

36. N. Ait Ahmed, H. Hammache, L. Makhloufi, M. Eyraud, S. Sam, A. Keffous, N. Gabouze, Vacuum.120, 100 (2015)

37. J. B. Raoof, R. Ojani, S. Rachid-Nadimi, Electrochim. Acta. 49, 271 (2004)

38. J. B. Raoof, R. Ojani, A. Kiani, J. Electroanal. Chem. 515, 45 (2001)

39. S.C. Hsu, H.T. Cheng, P.X. Wu, C.J. Weng, K.S. Santiago, J.M. Yeh, Electrochim. Acta. 238, (2017) 246-256 


\section{Figures}

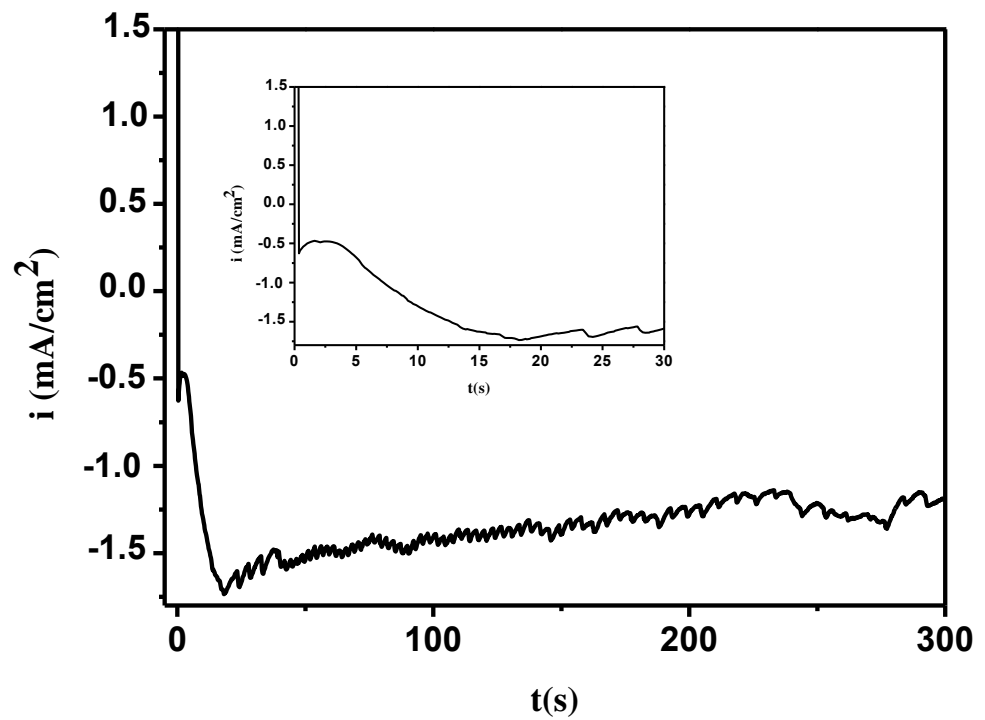

Fig.1 Chronoamperometric curve recorded on a glassy carbon electrode in $5 \mathrm{mM} \mathrm{Zn}\left(\mathrm{NO}_{3}\right)_{2}, 6 \mathrm{H}_{2} \mathrm{O}$ and $0.1 \mathrm{M} \mathrm{KNO}_{3}$ at $-1.1 \mathrm{~V}$ vs. SCE (inset: magnified view for a shorter deposition time).

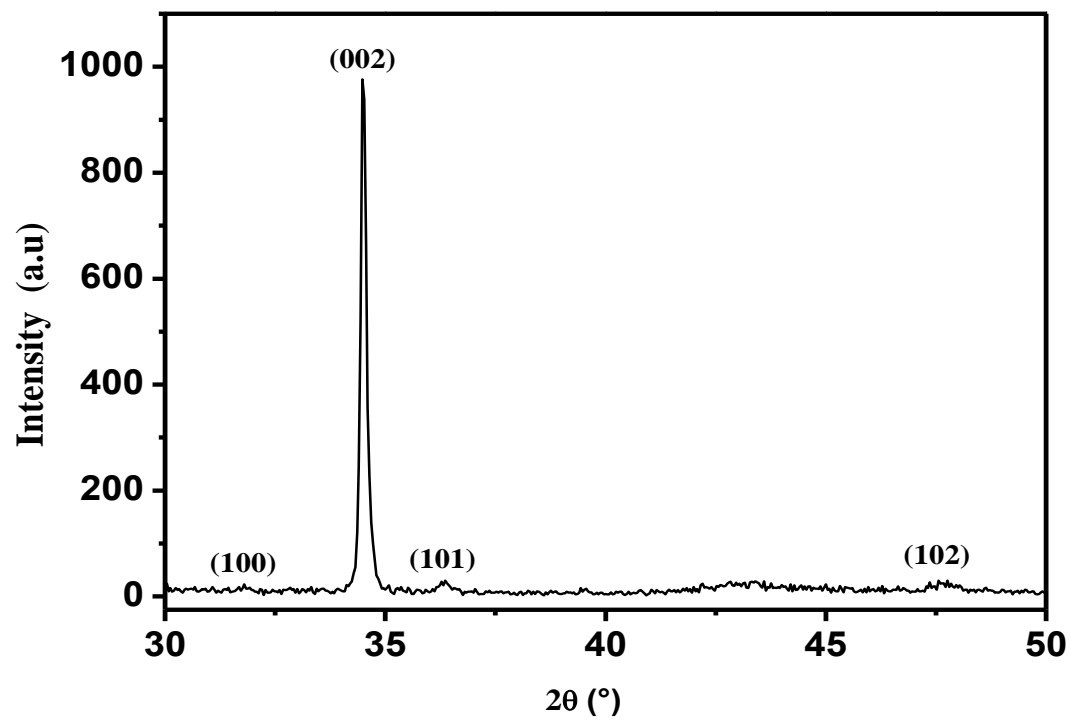

Fig.2 XRD pattern of the as- prepared $\mathrm{ZnO}$ obtained from $5 \mathrm{mM} \mathrm{Zn}\left(\mathrm{NO}_{3}\right)_{2}, 6 \mathrm{H}_{2} \mathrm{O}$ and $0.1 \mathrm{M} \mathrm{KNO}_{3}$ at $-1.1 \mathrm{~V}$ vs. SCE during $5 \mathrm{~min}$. 

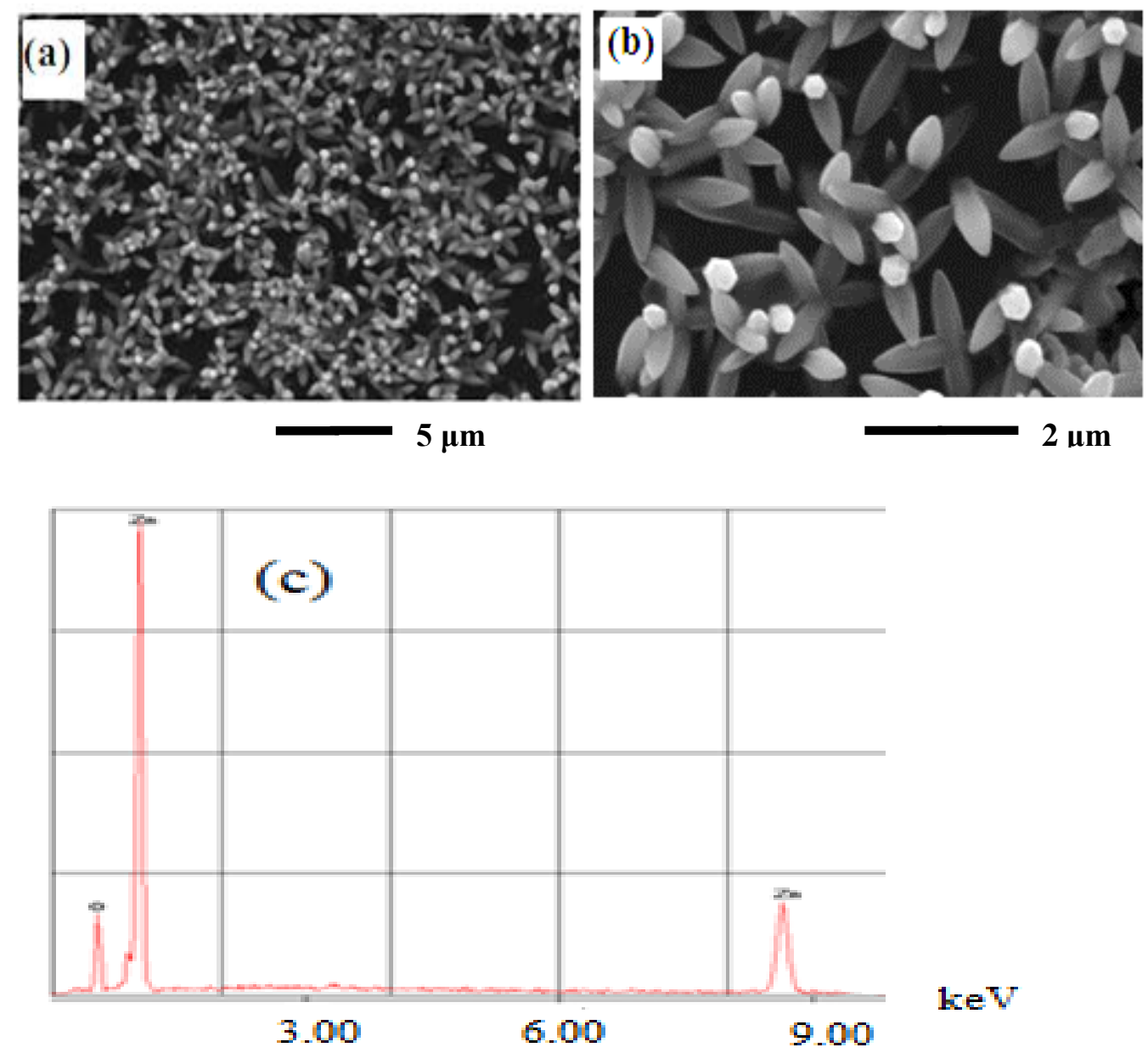

Fig.3 a and b SEM images obtained at 2 magnifications for the as- prepared $\mathrm{ZnO}$ grown on glassy carbon substrate at $-1.1 \mathrm{~V}$ vs. SCE for $5 \mathrm{~min}$ and $\mathbf{c}$ corresponding Energy-dispersive X-ray (EDX) spectrum

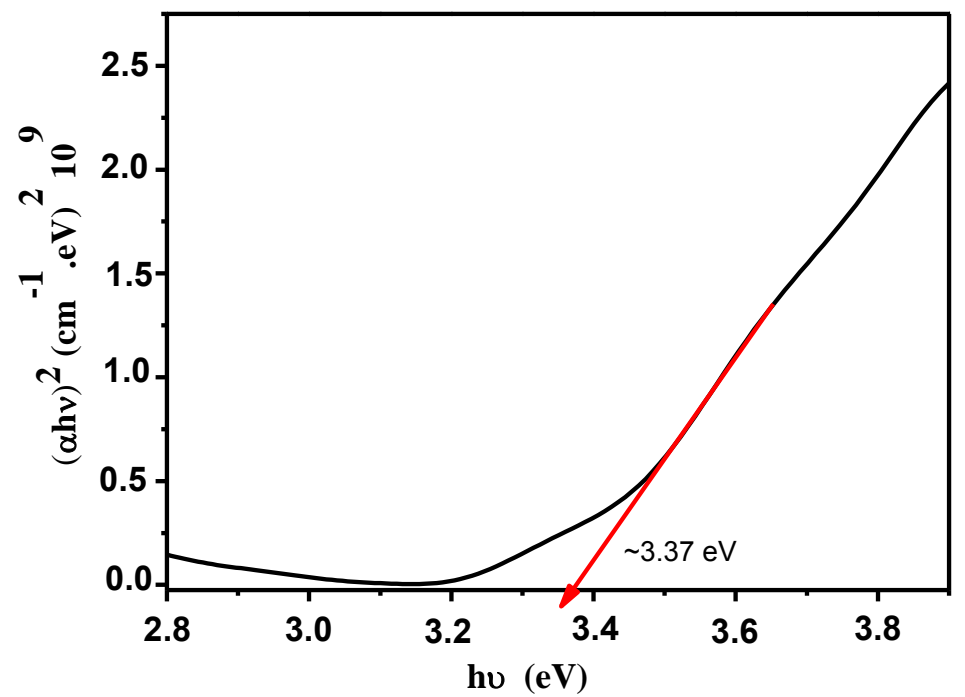

Fig.4 Tauc plot of $(\alpha h v)^{2}$ vs. photon energy $(\mathrm{h} v)$ of the as-prepared $\mathrm{ZnO}$ deposit on CGE. 


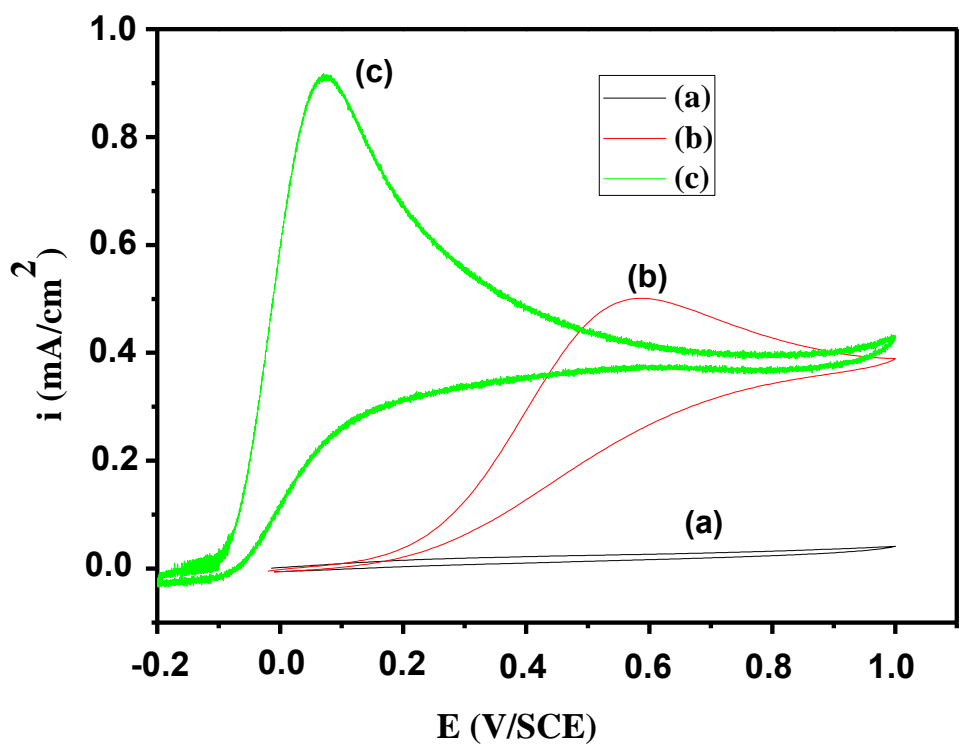

Fig. 5 Cyclic voltammograms on bare GCE without (curve a) and with (curve b) $5 \mathrm{mM}$ ascorbic acid in $0.1 \mathrm{M}$ phosphate buffer solution ( $\mathrm{pH}$ 6.8). Curve $\mathrm{c}$ is obtained on $\mathrm{ZnO} / \mathrm{GCE}$ in $5 \mathrm{mM}$ ascorbic acid in $0.1 \mathrm{M}$ phosphate buffer solution (pH 6.8). Scan rate: $8 \mathrm{mV} \mathrm{s}^{-1}$.

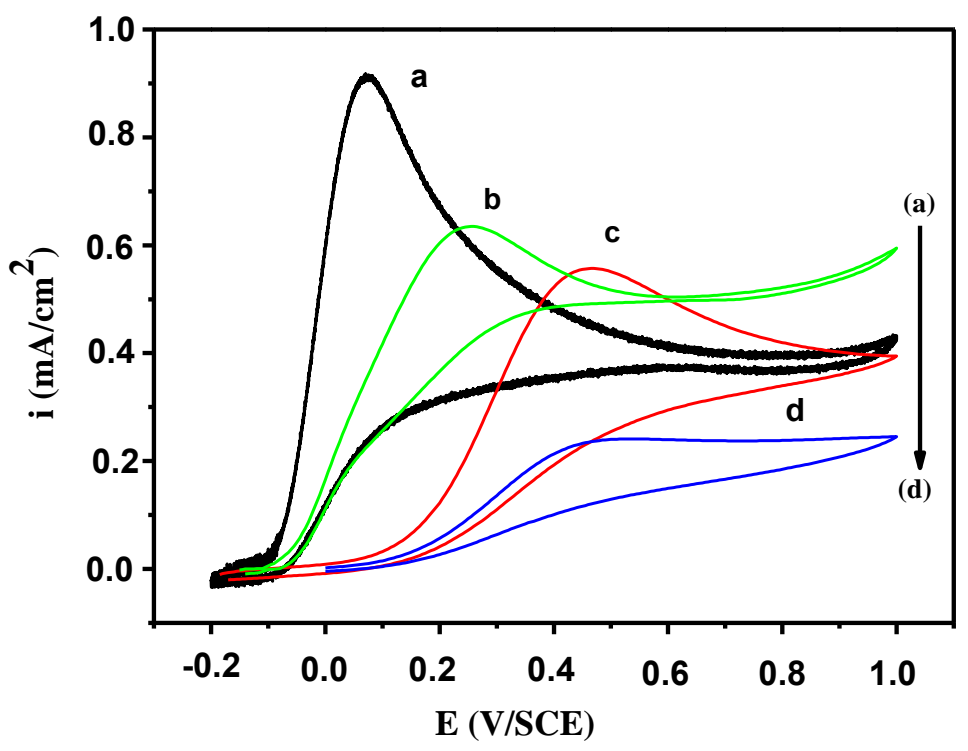

Fig. 6 Cyclic voltammograms on $\mathrm{ZnO} / \mathrm{GCE}$ in $5 \mathrm{mM} \mathrm{AA}+0.1 \mathrm{M}$ phosphate buffer solution (pH 6.8), at $8 \mathrm{mV} \mathrm{s}^{-1}$. The $\mathrm{ZnO}$ deposits were obtained for various deposition times a $5 \mathrm{~min}, \mathbf{b} 10 \mathrm{~min}, \mathbf{c} 15 \mathrm{~min}$, d 20 min, at -1.1 V vs. SCE. 

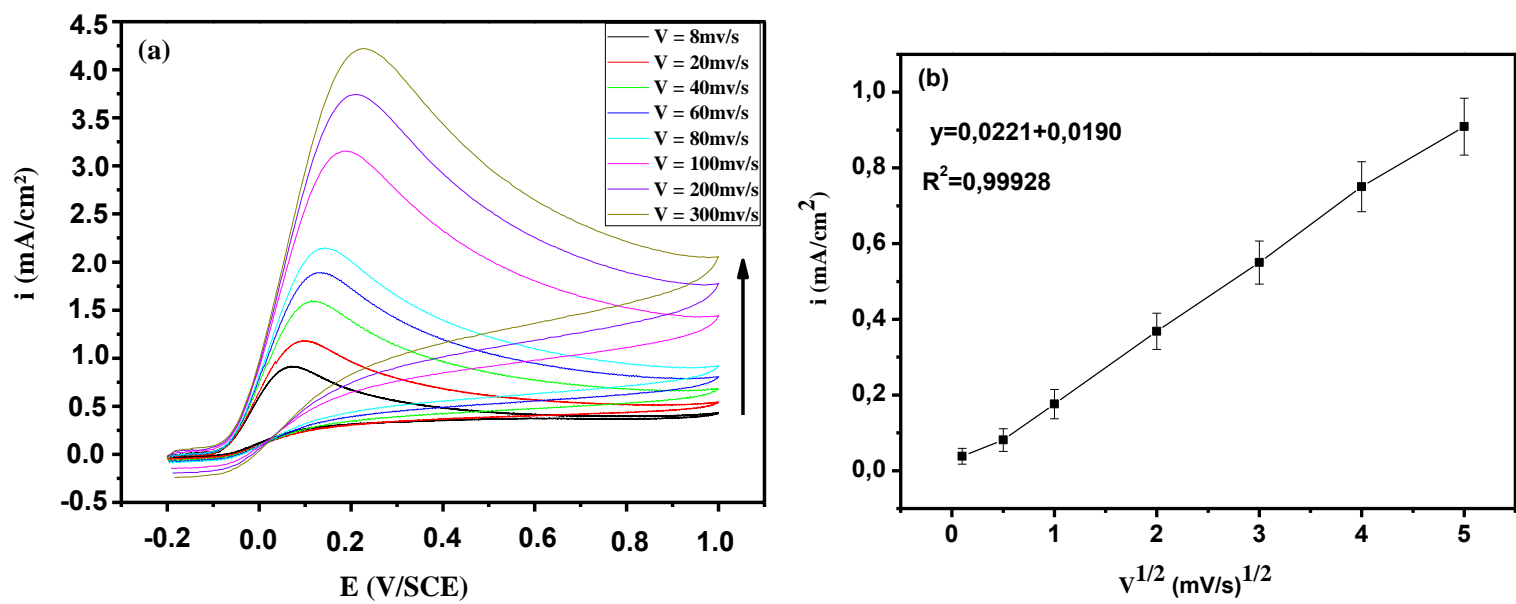

Fig. 7 a Cyclic voltammograms of 5.0 mM AA in $0.1 \mathrm{M}$ phosphate buffer solution (pH 6.8) at the ZnO/GCE with different scan rates a 8, b 20, c 40, d 60, e 80, f 100, g 200, h 300 mV.s ${ }^{-1}$. bVariation of the anodic currents versus the square root of the scan rates.
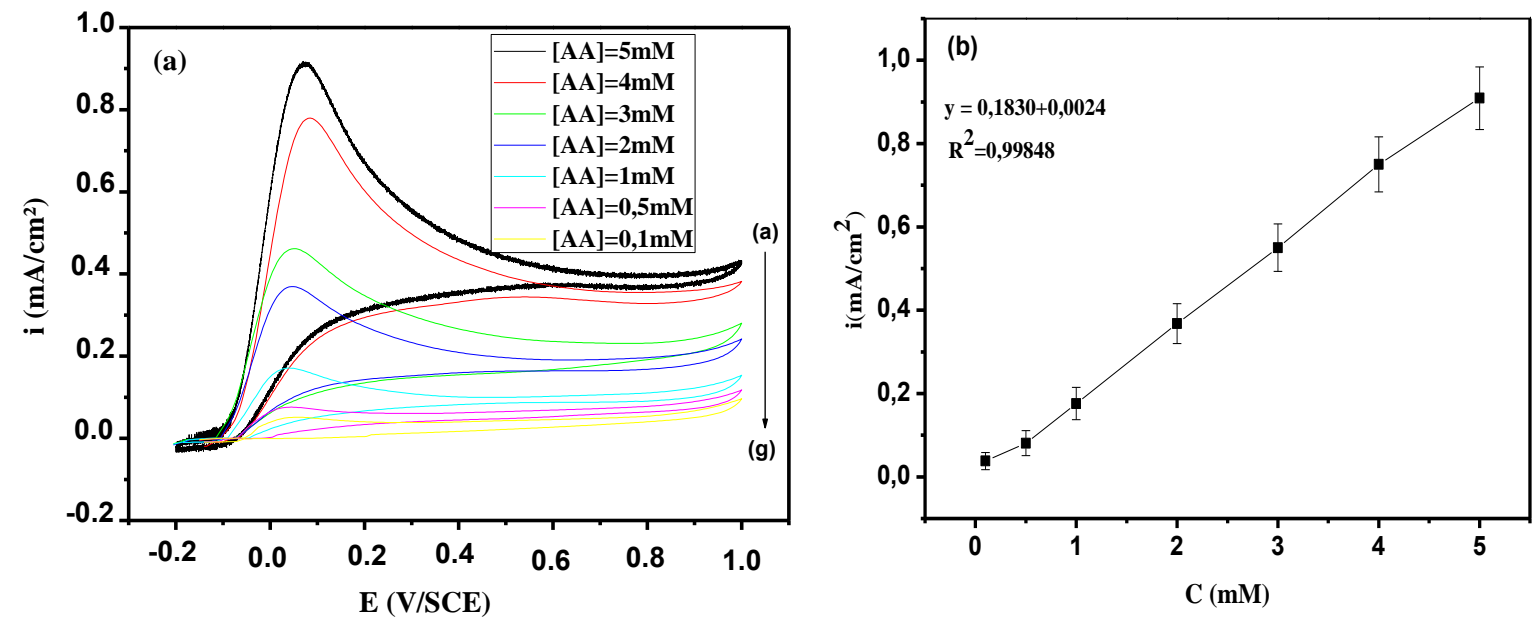

Fig. 8 a Cyclic voltammograms on $\mathrm{ZnO} / \mathrm{GCE}$ at $-1.1 \mathrm{~V}$ for $5 \mathrm{~min}$ in $0.1 \mathrm{M}$ phosphate buffer solution ( $\mathrm{pH}$ 6.8) containing various ascorbic acid concentrations. From a to g, AA concentrations are respectively $0.1,0.5,1,2,3,3,4,5 \mathrm{mM}$. Scan rate: $8 \mathrm{mV} \mathrm{s}^{-1}$. b The corresponding plots of peak currents as a function of AA concentration. 